\title{
Adsorptive Removal of Mercury by Using New Nano Adsorption
}

\author{
Zahra Abbasi $^{1{ }^{1 *},}$, MokhtarAghababaei ${ }^{2}$ \\ ${ }^{1}$ Young Researchers and Elite club, Ilam Branch, Islamic Azad University, Iran \\ ${ }^{2}$ Department of Chemistry, Shahreza Branch, Islamic Azad University, Isfahan, Iran \\ *Corresponding Author: zahra.abbasi886@gmail.com
}

Copyright (c) 2014Horizon Research Publishing All rights reserved

\begin{abstract}
In the present work nano-hydroxyapatite/ Carboxymethyl Cellulose (n-HApCMC) composite was synthesized by precipitation method and was characterized by Fourier transform infrared (FT-IR) spectroscopy, X-ray diffraction (XRD) crystallography and scanning electron microscopy (SEM). The n-HApCMC composite was tested for the adsorption of Mercury from aqueous solution and compared its removal capacity with nano-hydroxyapatite (HAp). Effect of various physico-chemical parameters such as $\mathrm{pH}$, adsorbent dose, contact time, initial metal ion concentration and temperature on adsorption of metal ions onto n-HApCMC composite was investigated. The adsorption process followed pseudo-second order kinetics and intra-particle diffusion model. Equilibrium data were fitted well in the Langmuir and Freundlich isotherm models. The thermodynamic analysis also established that the adsorption process was endothermic and spontaneous.
\end{abstract}

Keywords Adsorption, Heavy metals, Isotherm, Nano-Hydroxyapatite/Cellulose

\section{Introduction}

Heavy metal pollution has become an environmental problem throughout the world because heavy metals can be accumulated into the food chain and cause serious problems, not only for ecosystems but also for human health. The selective removal of industrial heavy metals from liquid waste is consequently the subject of considerable ecological and economic interest [1]. Heavy metal ions, aromatic compounds (including phenolic derivatives, and polycyclic aromatic compounds) and dyes are often found in the environment as a result of their wide industrial uses. Wastes containing soluble toxic heavy metals require concentration of the metals into a smaller volume followed by recovery and secure disposal. Heavy metals can be removed by adsorption on solid matrices.

Mercury $(\mathrm{Hg})$ emissions from waste incineration are a global problem, indicated by that nearly half of the $\mathrm{Hg}$ emissions reaching the Arctic originates from waste incineration [9]. In most countries, the total $\mathrm{Hg}$ emissions from waste incineration are largely underestimated because of poor knowledge about $\mathrm{Hg}$ content in wastes and due to economic reasons there are no or only limited analyses available on $\mathrm{Hg}$ content in flue gases from a majority of the waste incineration plants in operation [10].

Hydroxyapatite $\mathrm{Ca}_{10}\left(\mathrm{PO}_{4}\right)_{6}(\mathrm{OH})_{2}$ (HAp) is a main mineral constituent of teeth, bones and phosphate mineral rocks. It belongs to apatite mineral family. HAp was shown to be efficient for the removal of many toxic metal ions such as lead, cobalt, nickel, copper, zinc, cadmium and uranium in aqueous solutions [2], [4], [8], [11], [12], [14]. However, characteristic of HAp existing in the form of white powder therefore isolating the suspended fine solids from aqueous solutions after adsorption of metal ions is not easy [3]. Cellulose, the most abundantly available carbohydrate polymer in nature, is continually replenished by the photosynthetic reduction of $\mathrm{CO}_{2}$ catalyzed by sunlight - a mechanism that is highly beneficial in mitigating environmental problems resulting from increased atmospheric $\mathrm{CO}_{2}$. The annual net yield of photosynthesis is 1.8 trillion tonnes of biodegradable substances, about $40 \%$ of which is estimated to be cellulose [13]. Hence the general aim of the study is to investigate adsorption capability of cellulose composites made withnano-hydroxyapatite which, biocompatibility, biodegradability, etc than the individual components and hence be utilized at field conditions. Hybrid polymeric composites namely nano-hydroxyapatite/ Carboxymethyl Cellulose (n-HApCMC) were prepared and used for the removal of $\mathrm{Hg}$ (II) from drinking water which has not been reported so far. Various parameters namely contact time, $\mathrm{pH}$, coions and temperature were optimized for maximum sorption. The best fit isotherm was identified for the sorption. Suitable mechanism of $\mathrm{Hg}$ (II) removal was proposed.

\section{Experimental}

\subsection{Materials}


Carboxymethyl cellulose (CMC) provided by Floka company whose molecular weight is about $4.2 \times 10^{8}$, potassium dichromate, calcium nitrate, Ammonium dihydrogen phosphate, ammonia were purchased from Merck (Germany) and all other chemicals used were of analytical.

\subsection{Methods}

\subsubsection{Synthesis of Nano-Hydroxyapatite/ Carboxymethyl Cellulose (N-Hapcmc) Composite}

n-HAp was synthesized by the reaction of calcium nitrate and ammonium dihydrogen phosphate at a stoichiometric $\mathrm{Ca} / \mathrm{P}$ ratio of 1.67 , with the $\mathrm{pH}$ value during mixing, being maintained maintained $10-11$ by the addition of ammonia solution. The resulting precipitate was rinsed with water until the wash water was neutral and then dried at $80{ }^{\circ} \mathrm{C}$ [7]. The corresponding $\mathrm{n}-\mathrm{HAp} / \mathrm{CMC}$ composites were prepared by the precipitation method. The aqueous solution of Ammonium dihydrogen phosphate was added to the mixture of aqueous solution of $\mathrm{Ca}\left(\mathrm{NO}_{3}\right)_{2}$ with $\mathrm{CMC}$ in the ratio $3: 2$. The precipitate formed was rinsed with water to bring the $\mathrm{pH}$ level to 7 . The precipitate obtained was dried at $80{ }^{\circ} \mathrm{C}$ to get $\mathrm{n}$-HApCMC composites.

\subsubsection{Characterization of Materials}

Characterization -n-HApCMC and its structural and morphological analysis by SEM, XRD and FTIR techniques. The phases present in the magnetic materials were analyzed using a powder X-ray diffract meter (XRD) Philips (Holland), model $\mathrm{X}^{\prime}$ Pert with $\mathrm{CuK}_{\alpha 1}$ radiation $(\lambda=1.5406$ $\AA$ ), and the X-ray generator was operated at $40 \mathrm{KV}$ and 30 $\mathrm{mA}$. Diffraction patterns were collected from $2 \theta=10^{\circ}-50^{\circ}$.

Fourier transform infrared (FT-IR) spectra were recorded on a FT-IR spectrometer (Perkin Elmer) with a spectral resolution of $4 \mathrm{~cm}^{-1}$ in the wave number range of $500-4000$ $\mathrm{cm}^{-1}$. The samples and $\mathrm{KBr}$ were fully dried before the FT-IR analyses to exclude the influence of water.

Scanning electronic microscopy (SEM), the morphology of the surface of -n-HApCMC was investigated using a scanning electronic microscope of XL30 type (Netherland). The catalyst was covered with pure metallic Ag. The laying down of Ag was carried out using evaporation of the metal under a high vacuum, to give a thickness of around $100 \mathrm{~A}^{\circ}$.

$\mathrm{pH}$ adjustments were made with digital $\mathrm{pH}$-meter (Sartorius, ModelPP-20) using $\mathrm{HCl}\left(0.1 \mathrm{~mol} \mathrm{~L}^{-1}\right)$ and $\mathrm{NaOH}$ $\left(0.1 \mathrm{~mol} \mathrm{~L}^{-1}\right)$. Mercury content in each experiment were determined with flame atomic absorption spectrophotometer (Perkin Elmer, Analyst 100).

\section{Results and Discussions}

\subsection{Characterization of Materials}

The IR spectra of n-HApCMC (A), CMC (B) and n-HAp
(C) were recorded in the region of $500-4000 \mathrm{~cm}^{-1}$ and are shown in Fig. 1. The spectra of n- HAp showed a broad band at $1203 \mathrm{~cm}^{-1}$ due to asymmetric stretching of $\mathrm{PO}_{4}{ }^{3-}$ and corresponding symmetric stretching was observed at 875 $\mathrm{cm}^{-1}$. The absorption band at $1487 \mathrm{~cm}^{-1}$ suggested the presence of $\mathrm{CO}_{3}^{-2}$ [7], which was supposed to have come from atmosphere during the precipitation process. The broad band at 3500 to $3200 \mathrm{~cm}^{-1}$ and $1766 \mathrm{~cm}^{-1}$ was due to stretching and bending of $\mathrm{O}-\mathrm{H}$ groups, respectively, present in n-Hap [5]. The FT-IR spectra of n-HApCMC showed a band at $1032 \mathrm{~cm}^{-1}$ which was due to stretching vibration of $\mathrm{C}-\mathrm{O}-\mathrm{C}$ group of $\mathrm{CMC}$ confirms formation of composite. The peak of $\mathrm{PO}_{4}{ }^{3-}$ group shifted from 1203 to $1132 \mathrm{~cm}^{-1}$ due to interaction with $\mathrm{CMC}$. The stretching and bending vibration mode of $-\mathrm{OH}$ group of $\mathrm{CMC}$ occurred at 3452 and $1627 \mathrm{~cm}^{-1}$, respectively which was overlapped with the bands of $\mathrm{O}-\mathrm{H}$ groups in $\mathrm{n}-\mathrm{HApCMC}$ composite.

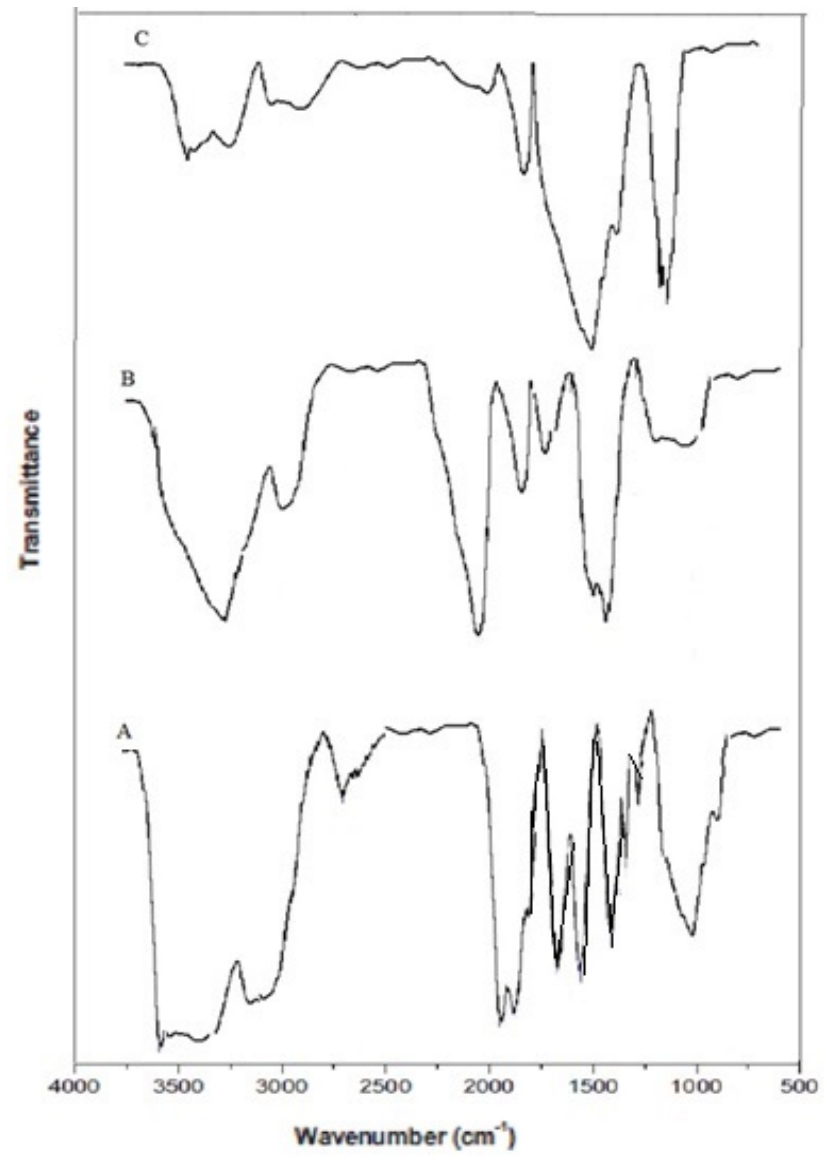

Figure 1. Infrared spectra of n-HApCMC composite (a), CMC (b) and nHap (c)

The characteristics of n-HAp, n-HApC and n-HApCs composites are shown in Fig. 2. In the XRD pattern of n-HAp, the crystalline peaks at $2 \theta=25.9^{\circ}, 31.9^{\circ}, 32^{\circ}$, $34.5^{\circ}$ and $40^{\circ}$ confirm the formation of hydroxyapatite. Crystalline peaks of In Fig. 2B, two main diffraction peaks of CMC at $2 \theta=32^{\circ}$ and $46^{\circ}$ can be found.n-HAp at $2 \theta=$ $26^{\circ}, 32^{\circ}, 33.1^{\circ}, 34.2^{\circ}, 39.9^{\circ}$ and $46^{\circ}$ were found in n-HApCMC. This indicated that there was no marked 
change in the peak structure after the composite formation and confirms that the crystal structure of n-HAp is retained in $\mathrm{n}-\mathrm{HApCMC}$ composites.

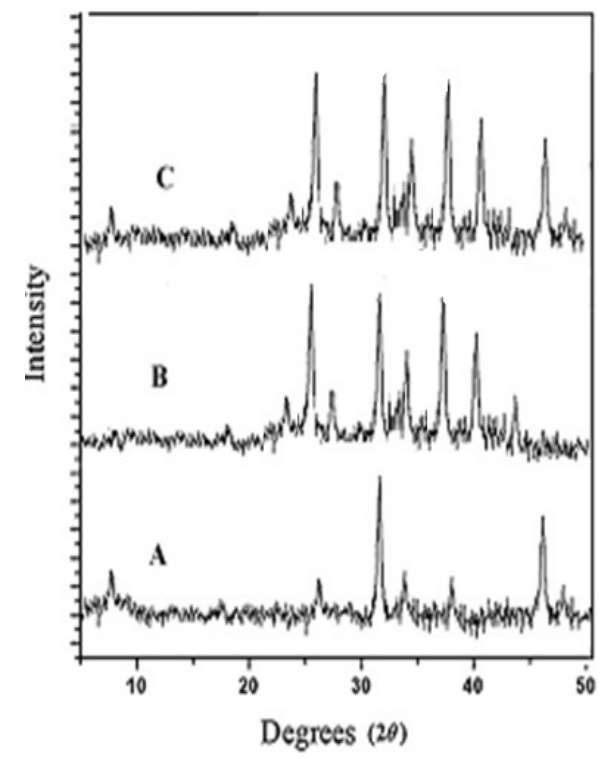

Figure 2. XRD spectra of CMC (a), HAp (b) and n-HApCMC (c)

Fig. 3 shows the morphology of n-HAp (a) and n-HApCMC composite (b). The n-HAp powder exhibited as particles but in case of n-HapCMC composite aggregates appeared and film of CMC over n-HAp, confirmed the formation of n-HApCMC composite.
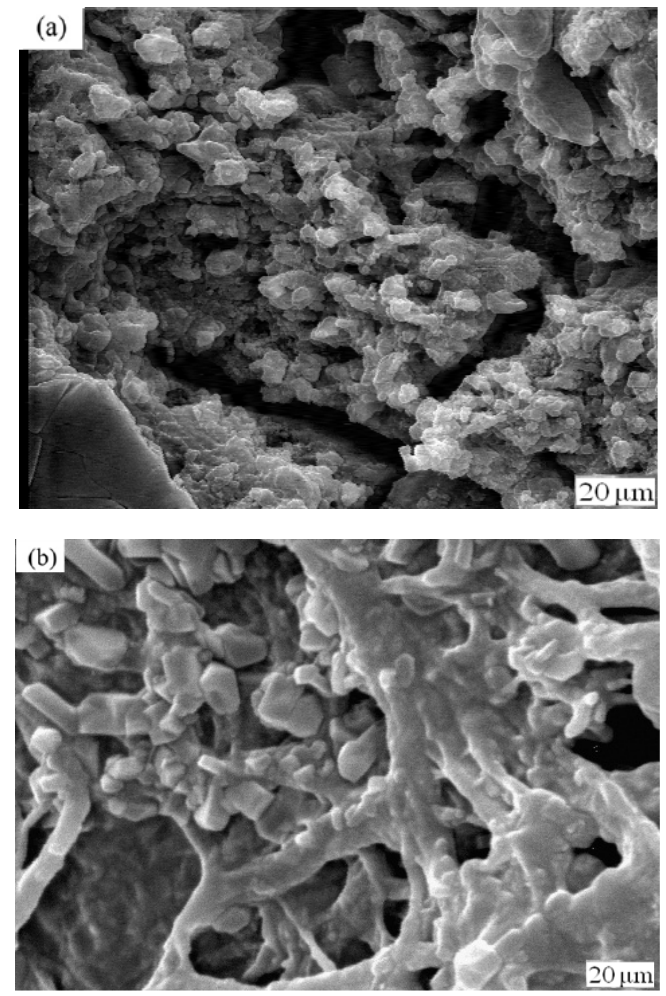

Figure 3. SEM micrograph of n-HAp (a) and n-HApCMC composite (b)

\subsection{Adsorption Isotherms}

The adsorption isotherms were obtained by employing $200 \mathrm{mg}$ of $\mathrm{n}$-HapCMC composite and $25 \mathrm{~mL}$ of Waste solution with different concentrations $(10,20,30,40,50,60$, $70,80,90$ and $100 \mu \mathrm{g} \mathrm{mL}^{-1}$ ). These solutions were stirred in a mechanical shaker until they reached adsorption equilibrium. The system was shaken for $90 \mathrm{~min}$ and then both phases were separated by filtration. The metal content of the filtrate was determined by atomic spectrometry. Fig. 4 shows equilibrium adsorption isotherm of $\mathrm{Hg}$ (II) on n-HapCMC composite at $298{ }^{\circ} \mathrm{K}$. The equilibrium adsorption density $\mathrm{q}_{\mathrm{e}}$ is increased with the increase in $\mathrm{Hg}(\mathrm{II})$ concentration. At low equilibrium heavy metals concentrations $\mathrm{C}_{\mathrm{e}}$, the equilibrium adsorption densities $\mathrm{q}_{\mathrm{e}}$ of the $\mathrm{n}$-HapCMC composite reach almost the same $\mathrm{q}_{\mathrm{e}}$ as those at high equilibrium $\mathrm{Hg}(\mathrm{II})$ concentrations. It indicates that n-HapCMC composite have high adsorption density even at low equilibrium $\mathrm{Hg}(\mathrm{II})$ concentrations. Fig. 4 shows the effect of heavy metals concentration on n-HapCMC composite adsorption. An increase in initial concentration of heavy metals led to an increase in the adsorption capacity of heavy metals on n-HapCMC composite.

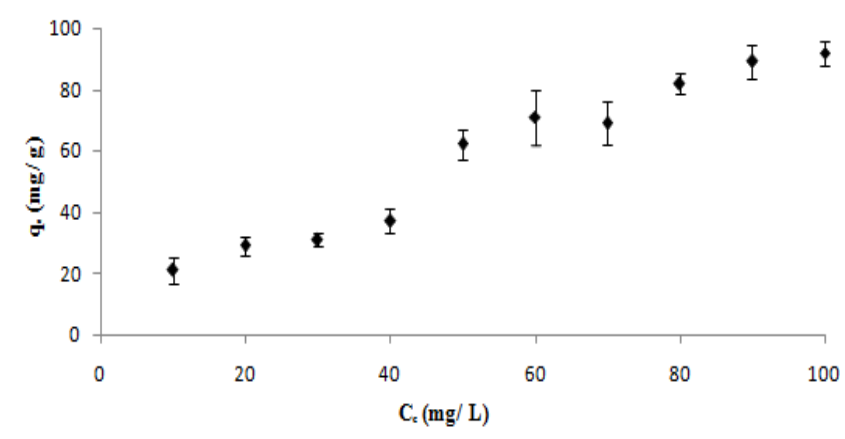

Figure 4. Equilibrium adsorption isotherm of $\mathrm{Hg}$ (II) on n-HApCMC

This indicates that the initial concentration of heavy metals played an important role in the adsorption capacity of heavy metals on adsorbent. The dotted lines in Figs. 5 and 6 represent a linear regression fit to the results for both isotherms. However, since adsorption data are of a nonlinear nature, nonlinear regressions are also performed on each set of data points. These nonlinear regression fits are represented as solid lines in Figs. 5 and 6.

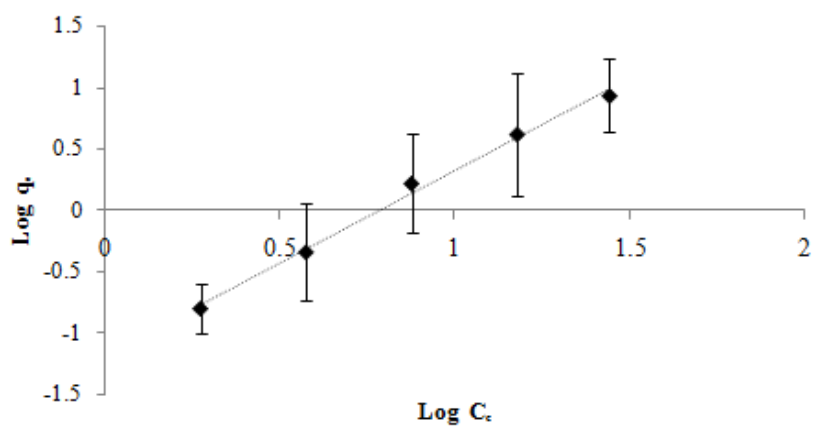

Figure 5. Freundlich adsorption isotherm at $298^{\circ} \mathrm{K}$ 


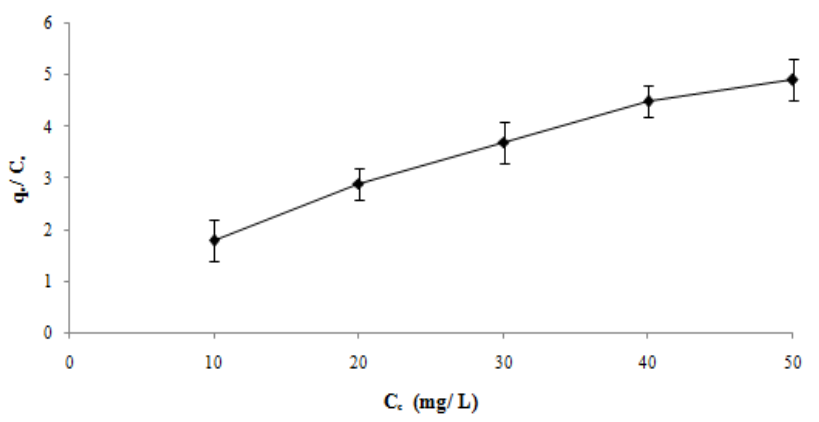

Figure 6. Langmuir adsorption isotherm at $298^{\circ} \mathrm{K}$

The correlation coefficients obtained with both kinds of regression for both adsorption isotherms are summarized in Table 1. The correlation coefficient values in Table 1 indicate that the data fit the Langmuir isotherm better than the Freundlich isotherm, both in case of linear and nonlinear regression.

Table 1. Freundlich and Langmuir adsorption isotherm constants

\begin{tabular}{|c|ccc|ccc|}
\hline Metal ions & \multicolumn{3}{|c|}{ Langmuir constants } & \multicolumn{4}{c|}{ Freundlich constants } \\
\hline \multirow{3}{*}{$\mathrm{Hg}$ (II) } & $\begin{array}{c}\mathrm{Q}^{\circ} \\
(\mathrm{mg} / \mathrm{g})\end{array}$ & $\begin{array}{c}\mathrm{b}(\mathrm{L} / \\
\mathrm{mg})\end{array}$ & $\mathrm{R}^{2}$ & $\begin{array}{c}\mathrm{K}_{\mathrm{F}} \\
(\mathrm{L} / \mathrm{mg})\end{array}$ & $\mathrm{n}$ & $\mathrm{R}^{2}$ \\
\cline { 2 - 8 } & 9.03 & 0.276 & 0.998 & 2.13 & 1.82 & 0.997 \\
\hline
\end{tabular}

\section{3. pH Optimization}

The removal of $\mathrm{Hg}(\mathrm{II})$ at different $\mathrm{pH}$ was studied in batch mode. A $25-\mathrm{ml}$ of test solution of fixed concentrations was treated with $200 \mathrm{mg}$ of n-HapCMC composite and agitated intermittently for $45 \mathrm{~min}$. The contact time and conditions were selected on the basis of preliminary experiments, which demonstrated that equilibrium was established in $45 \mathrm{~min}$. After this period the solution then both phases were separated by filtration. The metal content of the filtrate was determined by atomic spectrometry. The metal concentration retained in the sorbent phase $\left(q_{\mathrm{e}}, \mathrm{mg} / \mathrm{g}\right)$ was calculated by using Eq. (1)

$$
q_{e}=\frac{\left(C_{0}-C_{e}\right) V}{m}
$$

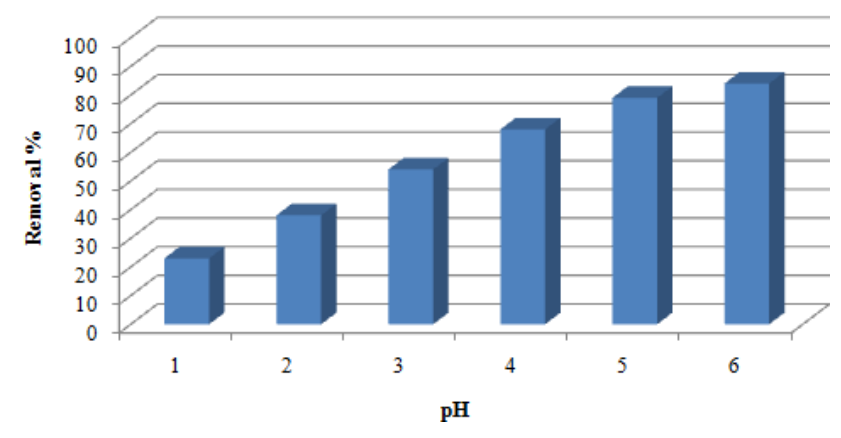

Figure 7. Effect of $\mathrm{pH}$ on adsorption of $\mathrm{Hg}$ (II) on n-HApCMC

Where $C_{0}$ and $C_{\mathrm{e}}$ are the initial and final (equilibrium) concentrations of the metal ion in solution (M), $V$ the solution volume (l) and $m$ is the mass of n-HapCMC composite $(\mathrm{g})$. To study the effect of $\mathrm{pH}$ on adsorption, experiments were carried out in the $\mathrm{pH}$ range $1-9$ for $\mathrm{Hg}(\mathrm{II})$. Fig. 7 shows that the removal of metal ions was increased with increasing initial $\mathrm{pH}$ of metal ion solution and maximum value was reached at5-6 for $\mathrm{Hg}(\mathrm{II})$.

\subsection{Kinetic Modeling in a Batch System}

In order to investigate the mechanism of adsorption kinetic models are generally used to test experimental data. Pseudo-first-order and pseudo-second-order equations can be used assuming that the measured concentrations are equal to surface concentrations. The pseudo-first-order rate Lagergren model is:

$$
\frac{d q}{d t}=k_{1, a d s}\left(q_{e}-q\right)
$$

Where $\mathrm{q}(\mathrm{mg} / \mathrm{g})$ is the amount of adsorbed heavy metals on the adsorbent at time $t$ and $\mathrm{k}_{1, \text { ads }}\left(\mathrm{min}^{-1}\right)$ is the rate constant of first-order adsorption. The integrated form of Eq. (2) is:

$$
\log \left(q_{e}-q\right)=\log q_{e}-\frac{k_{1, a d s}}{2.303} t
$$

$\mathrm{q}_{\mathrm{e}}$ the equilibrium sorption uptake, is extrapolated from the experimental data at time $t=$ infinity. A straight line of $\log \left(\mathrm{q}_{\mathrm{e}}-\mathrm{q}\right)$ versus $t$ suggests the applicability of this kinetic model. $\mathrm{q}_{\mathrm{e}}$ and $\mathrm{k}_{1, \text { ads }}$ can be determined from the intercept and slope of the plot, respectively. The pseudo-second order kinetic model is expressed as:

$$
\frac{d q}{d t}=k_{2, a d s}\left(q_{e}-q\right)^{2}
$$

Where $\mathrm{k}_{2, \text { ads }}(\mathrm{g} / \mathrm{mg} \mathrm{min})$ is the rate constant of second-order adsorption. The integrated form of Eq. (4) is:

$$
\frac{1}{q_{e}-q}=\frac{1}{q_{e}}+k_{2, a d s} t
$$

Eq. (5) can be rearranged and linearized to obtain:

$$
\frac{t}{q}=\frac{1}{k_{2, a d s} q_{e}^{2}}+\frac{1}{q_{e}} t
$$

The plot $t$ / $q$ versus $t$ should give a straight line if second order kinetic model is applicable and $\mathrm{q}_{\mathrm{e}}$ and $\mathrm{k}_{2 \text {,ads }}$ can be determined from the slope and intercept of the plot, respectively. It is important to notice that for the application of this model the experimental estimation of $\mathrm{q}_{\mathrm{e}}$ is not necessary.

\subsection{Equilibrium Modeling in a Batch System}

Analysis of equilibrium data is important for developing an equation that can be used to compare different biomaterials under different operational conditions and to design and optimize an operating procedure. The Langmuir and Freundlich equations are commonly used for describing adsorption equilibrium for water and wastewater treatment applications. Two important physicochemical aspects for the evaluation of the adsorption process as a unit operation are the equilibrium of the adsorption and the kinetics. Equilibrium studies give the capacity of the adsorbent. The 
equilibrium relationships between the adsorbent and the adsorbate are described by the adsorption isotherms. The adsorption curves were applied to both the Langmuir and Freundlich equations. The Freundlich isotherm model, which assumes that the adsorption occurs on heterogeneous surfaces, is often expressed as;

$$
q_{e}=K_{f}\left(C_{e}\right)^{1 / n}
$$

This equation is conveniently used in the following linear form:

$$
\ln q_{e}=\ln K_{f}+\frac{1}{n} \ln C_{e}
$$

Where $K_{f}$ is Freundlich isotherm constant $(L / g)$ and $n_{F}$ is Freundlich isotherm exponent. Values of $K_{F}$ and $n_{F}$ were calculated from the intercept and slope of plots $\operatorname{lnq}_{\mathrm{e}} \mathrm{vs} \ln \mathrm{C}_{\mathrm{e}}$ and a straight line indicates the confirmation of the Freundlich isotherm for adsorption. The value of $n_{F}$ should be greater than one confirming good adsorption of heavy metals onto n-HapCMC composite. Langmuir isotherm, which assume that a monolayer of heavy metals is formed on a relatively regular adsorbent surface, using the partially protonated groups of the adsorbent. The Langmuir isotherm has been successfully applied to many real sorption processes and is expressed as follows:

$$
q_{e}=\frac{Q^{0} b C_{e}}{1+b C_{e}}
$$

Where $\mathrm{q}_{\mathrm{e}}$ is the amount adsorbed at equilibrium $(\mathrm{mg} / \mathrm{g})$, $\mathrm{C}_{\mathrm{e}}$ the equilibrium concentration $(\mathrm{mg} / \mathrm{L}), \mathrm{b}$ a constant related to the energy or net enthalpy of adsorption $\left(\mathrm{L} / \mathrm{mg}\right.$ ), and $\mathrm{Q}_{0}$ the mass of adsorbed solute required to saturate a unit mass of adsorbent $(\mathrm{mg} / \mathrm{g}) . \mathrm{Q}_{0}$ represents a practical limiting adsorption capacity when the surface is fully covered with heavy metals and allows the comparison of adsorption performance, particularly in the cases where the adsorbent did not reach its full saturation in experiments. The Langmuir equation can be described by the linearized form as follows:

$$
\frac{C_{e}}{q_{e}}=\frac{1}{Q^{0} b}+\frac{C_{e}}{Q^{0}}
$$

By plotting $\left(\mathrm{C}_{\mathrm{e}} / \mathrm{q}_{\mathrm{e}}\right)$ versus $\mathrm{C}_{\mathrm{e}}, \mathrm{Q}^{0}$ and $\mathrm{b}$ can be determined if a straight line is obtained. The essential characteristics of Langmuir isotherm can be expressed in terms of a dimensionless constant, separation factor or equilibrium parameter, $R_{L}$, which is defined by:

$$
R_{L}=\frac{1}{1+b C_{0}}
$$

Where $\mathrm{b}$ is the Langmuir constant and $\mathrm{C}_{0}$ the initial heavy metals concentration $(\mathrm{mg} / \mathrm{L})$. $\mathrm{R}_{\mathrm{L}}$ value indicates the type of isotherm. According to [6]. $\mathrm{R}_{\mathrm{L}}$ values between 0 and 1 indicate favorable adsorption. For evaluating the adsorption kinetics the pseudo-first-order and pseudo-second-order kinetic models were used to fit the experimental data. It was observed that the $\mathrm{q}_{\mathrm{e}}$ values estimated by first-order kinetic model differ substantially from those measured experimentally, suggesting that the adsorption is not a first-order reaction. The correlation coefficients for the second-order kinetic model are nearly equal to 1 and the theoretical values of $\mathrm{q}_{\mathrm{e}}$ also agree very well with the experimental values. This suggests that the adsorption of heavy metals on n-HApCMC follows the second-order kinetic model. Fig. 8.

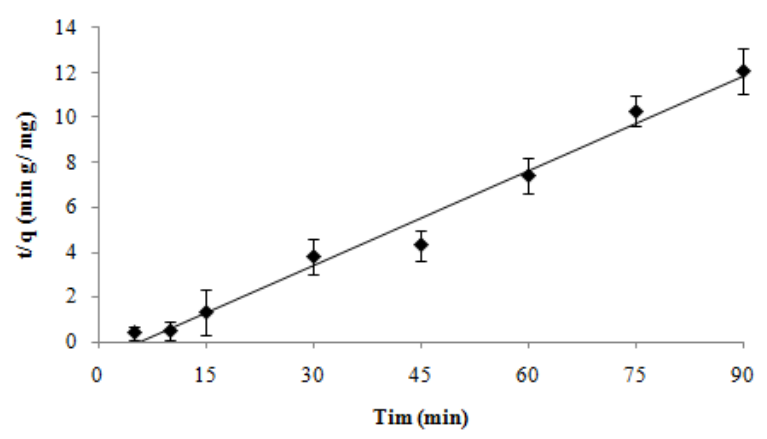

Figure 8. Pseudo-second-order kinetic model fitting for $\mathrm{Hg}$ (II) adsorption on n-HApCMC

The effect of temperature on the adsorption of heavy metals on $\mathrm{n}$-HApCMC was investigated by conducting experiments for $30 \mathrm{mg} / \mathrm{L}$ of initial metals ion concentrations at $298,303,308,313$, and $318^{\circ} \mathrm{K}$. It was observed that on increasing the temperature percentage removal of heavy metals increased. This showed that the adsorption process was endothermic in nature.

The thermodynamic parameters Gibb's free energy $\left(\Delta G^{\circ}\right)$, enthalpy $(\Delta \mathrm{H})$ and entropy $\left(\Delta \mathrm{S}^{\circ}\right)$ were calculated using the following equations:

$$
\begin{aligned}
& \ln \left(\frac{q_{e} m}{C_{e}}\right)=\frac{\Delta s^{0}}{R}+\frac{-\Delta H^{0}}{R T} \\
& \Delta G^{0}=\Delta H-T \Delta S^{0}
\end{aligned}
$$

Where $\mathrm{m}$ is the adsorbent dose $(\mathrm{g} / \mathrm{L}), \mathrm{C}_{\mathrm{e}}$ is concentration of metals ion $(\mathrm{mg} / \mathrm{L}), \mathrm{q}_{\mathrm{e}}$ is the amount of metals ion at equilibrium in unit mass of adsorbent $(\mathrm{mg} / \mathrm{g}), \mathrm{q}_{\mathrm{e}} / \mathrm{C}_{\mathrm{e}}$ is called the adsorption affinity. $\Delta \mathrm{H}, \Delta \mathrm{S}^{\circ}$ and $\Delta \mathrm{G}^{\circ}$ are change in enthalpy $(\mathrm{kJ} / \mathrm{mol})$, entropy $(\mathrm{J} /(\mathrm{mol} \mathrm{K}))$ and free energy $(\mathrm{kJ} / \mathrm{mol})$, respectively. $\mathrm{R}$ is the gas constant $(8.314 \mathrm{~J} / \mathrm{mol} \mathrm{K})$ and $\mathrm{T}$ is the temperature $(\mathrm{K})$.

Table 2. Thermodynamic parameters for adsorption of $\mathrm{Hg}$ (II) on n-HApCMC

\begin{tabular}{|c|c|c|ccccc|}
\hline Metal ions & $\begin{array}{c}\Delta \mathrm{H}^{\circ} \\
(\mathrm{kJ} / \mathrm{mol})\end{array}$ & $\begin{array}{c}\Delta \mathrm{S}^{\circ} \\
(\mathrm{Jmol} / \mathrm{K})\end{array}$ & \multicolumn{5}{|c|}{$\begin{array}{c}-\Delta \mathrm{G}^{\circ} \\
(\mathrm{kJ} / \mathrm{mol})\end{array}$} \\
\hline \multirow{2}{*}{$\mathrm{Hg}(\mathrm{II})$} & 42.769 & 171.759 & $298{ }^{\circ} \mathrm{K}$ & $303{ }^{\circ} \mathrm{K}$ & $308^{\circ} \mathrm{K}$ & $313^{\circ} \mathrm{K}$ & $318{ }^{\circ} \mathrm{K}$ \\
\cline { 4 - 8 } & & & 8.415 & 9.273 & 10.132 & 10.991 & 11.850 \\
\hline
\end{tabular}


The values of $\Delta \mathrm{H}$ and $\Delta \mathrm{S}^{\circ}$ were obtained from the slopes and intercepts of the Van't Hoff plots of $\ln \left(\mathrm{q}_{\mathrm{e}} \mathrm{m} / \mathrm{C}_{\mathrm{e}}\right)$ vs. 1/ $\mathrm{T}$, respectively, thereafter $\Delta \mathrm{G}^{\circ}$ values were determined from Eq. (12). The values of thermodynamic parameters are presented in Table 2. The results showed that the $\Delta \mathrm{G}^{\circ}$ values are negative and increased in their absolute values with temperature. This result suggested that a high temperature is favoured for the adsorption of heavy metals on n-HapCMC composite, indicated a spontaneous adsorption process. The values of heat of adsorption, $\Delta \mathrm{H}$ is positive for metals ion, indicated that the adsorption process of heavy metals on n-HapCMC composite was endothermic. A positive $\Delta \mathrm{S}$ suggested that heavy metals were not stable on the adsorption sites of n-HapCMC composite probably due to the increase in translational energy of metals ion.

\section{Conclusions}

This study showed that the binding of nano-HAp powder with cellulose makes it convenient to use practically and its removal capability was also retained in n-HApCMC which makes n- HApCMC composite as an effective adsorbent for the removal of $\mathrm{Hg}$ (II) from aqueous solution.

The adsorption process followed pseudo-second-order kinetics and obeyed Langmuir adsorption isotherm for metals ion studied. The negative values of $\Delta \mathrm{G}^{\circ}$ suggested that the adsorption was spontaneous in nature. The positive value of $\Delta \mathrm{H}$ and $\Delta \mathrm{S}$ indicated endothermic adsorption process and increased randomness at surface-solution interface, respectively.

\section{REFERENCES}

[1] Abbasi, Z. and M. Alikarami (2012) Kinetics and thermodynamics studies of acetic acid adsorption from aqueous solution by peels of banana. Biochemistry and Bioinformatics Vol. 1 (1), pp. $001-007$.
[2] Bailliez S, Nzihou A, Beche E, Flamant G (2004) Removal of Lead $(\mathrm{Pb})$ by hydroxyapatite sorbent. Process Saf Environ Protect 82:175-80.

[3] Choi S, Jeong Y (2008) The removal of heavy metals in aqueous solution by hydroxyapatite/cellulose composite. Fiber Polym 9:267-70.

[4] Corami A, Mignardi S, Ferrini V (2007) Copper and zinc decontamination from singleand binary-metal solutions using hydroxyapatite. J Hazard Mater 146: 164-70.

[5] Leyva AQG, Marrero J, Smichowski P, Cicerone D (1994) Sorption of antimony onto hydroxyapatite. Environ SciTechnol 28:1472-80.

[6] McKay G., Blair H.S., Garden J.R (1982) Adsorption of dyes on chitin. I. Equilibrium studiesJApplPolym Sci. 27: 3043

[7] Mobasherpour I, Heshajin MS, Kazemzadeh A, Zakeri M (2007) Synthesis of nanocrystalline hydroxyapatite by using precipitation method. J Alloy Compd 430:330-3.

[8] Mobasherpour I, Salahi E, Pazouki M (2011) Removal of nickel (II) from aqueous solutions by nano-crystalline calcium hydroxyapatite. J Saudi ChemSoc 15:105-12.

[9] Ngah W.S.W.N., Endud C.S., Mayanar E.R.,Polymers. 50 (2002) 181- 190.

[10] Pacyna E.G., Pacyna J.M.,N Pirrone N (2001) Atmospheric mercury emissions in Europe from anthropogenic sources.Atmos Environ 35:2987 -2996.

[11] Smiciklas I, Dimovic S, Plecas I, Mitric M (2006) Removal of $\mathrm{Co} 2+$ from aqueous solutions by hydroxyapatite. Water Res 40:2267-74.

[12] Simon FG, Birmann V, Peplinski B (2008) Uranium removal from groundwater using hydroxyapatite. ApplGeochem 23:2137-45.

[13] Wagner P.A, Little B.J, Hart K.R and Ray R.I (1996) Biodegradation of composite materials". IntBiodeteriorBiodegrad, 38:125-32.

[14] Zhu R, Yu R, Yao J, Mao D, Xing C, Wang D (2008) Removal of $\mathrm{Cd} 2+$ from aqueous solutions by hydroxyapatite. Catal Today 139:94-9. 